\title{
Genetic polymorphisms in TERT are associated with increased risk of esophageal cancer
}

\author{
Yifei Wu ${ }^{1, *}$, Mengdan Yan ${ }^{1,2, *}$, Jing Li ${ }^{1,2}$, Jingjie Li ${ }^{1,2}$, Zhengshuai Chen ${ }^{1,2}$, Peng Chen ${ }^{1,2,3}$, \\ Bin Li ${ }^{1,2}$, Fulin Chen ${ }^{1}$, Tianbo Jin ${ }^{1,2}$, Chao Chen ${ }^{1}$ \\ ${ }^{1}$ Key Laboratory of Resource Biology and Biotechnology in Western China (Northwest University), Ministry of Education, \\ Xi'an, Shaanxi 710069, China \\ ${ }^{2}$ Xi'an Tiangen Precision Medical Institute, Xi'an, Shaanxi 710075, China \\ ${ }^{3}$ Institution of Basic Medical Science, Xi'an Medical University, Xi'an, Shaanxi 710021, China \\ *These authors have contributed equally to this work \\ Correspondence to: Tianbo Jin, email: jtianbo@163.com.com \\ Chao Chen, email: chaochenxida@163.com \\ Keywords: TERT, SNP, esophageal cancer, susceptibility, northwest Chinese population \\ Received: August 26, $2016 \quad$ Accepted: December 13,2016 Published: January 02, 2017
}

\section{ABSTRACT}

Single nucleotide polymorphisms (SNPS) in TERT may be associated with susceptibility to esophageal cancer. In this study, we analyzed the association between TERT SNPs and risk of esophageal cancer in 386 esophageal cancer patients and 495 healthy subjects from the Xi'an area of China. Of the four SNPs examined, rs10069690 and rs2242652 were correlated with esophageal cancer risk. Additionally, after adjusting for age and gender, the " $T_{r s 10069690} A_{r s 2242652}$ ", " $T_{r s 10069690} G_{r s 2242652}$ " haplotypes were associated with an increased risk of esophageal cancer, while the and " $\mathrm{C}_{\mathrm{rs} 10069690} \mathrm{G}_{\mathrm{rs2242652}}$ " haplotype was associated with a decreased risk of esophageal cancer. These findings suggest that TERT polymorphisms may contribute to the development of esophageal cancer.

\section{INTRODUCTION}

Esophageal cancer is the sixth leading cause of cancer-related death worldwide, and an estimated 500,000 new cases are diagnosed each year [1]. In China, esophageal cancer was the fifth most commonly diagnosed cancer and the fourth leading cause of cancer-related death in 2009 [2]. Esophageal cancer is very aggressive and is associated with a poor prognosis [3]. Esophageal cancer can be categorized as one of two histological types, adenocarcinoma and squamous cell carcinoma (SCC), each of which have distinct etiologies and specific risk factors [4]. Esophageal squamous cell carcinoma (ESCC) accounts for more than 90 percent of esophageal cancers [5] and is the major histological subtype in East Asian countries [6]. Smoking and alcohol consumption are major risk factors for ESCC [7]. The incidence of esophageal cancer has increased markedly worldwide in recent decades, and this increase can be mainly attributed to higher incidences of esophageal adenocarcinoma in North America [8, 9], Europe [10], and Japan [11]. Meanwhile, the incidence of ESCC has remained stable or declined $[8,10]$.

Telomerase, a reverse transcriptase that carries its own templates, maintains telomere length by synthesizing telomeric DNA repeats. Many events can result in telomere dysfunctions, including gradual shortening caused by incomplete chromosome replication, oxidative DNA damage, or mutations in structural proteins, such as TERT [12]. TERT is the reverse transcriptase catalytic subunit of telomerase, and the activation of both TERT and telomerase plays a key role in cellular immortalization and transformation [13]. In addition, multiple independent variants at the TERT locus are associated with telomere length and risk of malignant tumors [14]. TERT uses the RNA subunit of telomerase as a template for the synthesis of single-stranded DNA in the telomeric region of the chromosome, resulting in tandem nucleotide repeats that prevent shortening of the chromosome. Telomerase activity, which is elevated in most cancer cells, may block apoptosis or senescence in cancer cells [15]. Several studies have shown that TERT promotes tumor invasion 
and metastasis in gastric, liver, and esophageal cancer [16-18].

In this study, we conducted an extensive association analysis to evaluate the roles of TERT gene polymorphisms and haplotypes on susceptibility to esophageal cancer in a population of northwestern Chinese patients from a single case-control study. Four TERT single nucleotide polymorphisms (SNPs) were examined in this association analysis in an attempt to identify markers that might guide intervention decisions and improve patient survival.

\section{RESULTS}

The genotypes of 881 participants, including 386 esophageal cancer patients and 495 controls, were analyzed in this study. Basic patient characteristics (gender and age) are listed in Table $1.79 .8 \%$ of the esophageal cancer patients were men and $20.2 \%$ were women, while $36.4 \%$ of the controls were men and $63.6 \%$ were women. The mean ages were $60.68( \pm 8.954)$ years for esophageal cancer patients and $54.48( \pm 9.438)$ years for controls.

Four SNPs in the TERT gene were genotyped in the esophageal cancer patients and the healthy controls. Table 2 summarizes the basic characteristics of these TERT SNPs in the study population. All four SNPs conformed to HWE in the control group $(p>0.05)$, and two-sided Pearson chi-square tests were used to identify differences in allele frequency distributions between esophageal cancer patients and controls. The rs10069690, rs2242652, and rs2853676 SNPs were associated with 1.70-fold (95\% CI, 1.33 - 12.18, $p=2.50 \mathrm{E}-05)$, 1.48-fold (95\% CI, $1.17-1.89, p=0.001)$, and 1.33 -fold $(95 \% \mathrm{CI}$, $1.04-1.70, \mathrm{P}=0.023$ ) increases in the risk of developing esophageal cancer, respectively. Two of these SNPs (rs10069690 and rs2242652) were still correlated with esophageal cancer in the allelic model after Bonferroni correction.

Next, we examined the association between TERT SNPs and esophageal cancer risk using genetic models (Table 3); $p$-values were calculated using the Wald test. The "T/C-T/T" genotype at the rs10069690 SNP increased the risk of esophageal cancer in the dominant model (OR $=1.95 ; 95 \% \mathrm{CI}, 1.43-2.73, p=5.89 \mathrm{E}-06)$, and the " $\mathrm{T}$ " allele increased the risk of esophageal in the log-additive model $(\mathrm{OR}=1.71 ; 95 \% \mathrm{CI}, 1.33-2.20, p=3.02 \mathrm{E}$ $05)$. These relationships in both the dominant model $(p$ $=4.33 \mathrm{E}-05)$ and the log-additive model $(p<0.001)$ remained significant after adjustments for age and gender.

For the rs2242652 SNP, the "G/A-A/A" genotype increased the risk of esophageal cancer 1.64-fold (95\% CI, $1.24-2.197 ; p=5.5 \mathrm{E}-04)$ in the dominant model, and the "A" allele increased the risk 1.48-fold (95\% CI, 1.18 - $1.93 ; p=0.001)$ in the log-additive model. In addition, after adjustment for age and gender, the "G/A-A/A" genotype increased the risk of lung cancer 1.59-fold $(p=$
$0.004)$ and the "A" allele increased the risk 1.48-fold $(p$ $=0.006)$.

Interestingly, a third SNP (rs2853676) was associated with susceptibility to esophageal cancer after adjustment for age and gender. Specifically, the " $\mathrm{C} / \mathrm{T}$ $\mathrm{T} / \mathrm{T}$ " genotype increased the risk of esophageal cancer in the dominant model $(\mathrm{OR}=1.44 ; 95 \% \mathrm{CI}, 1.05-1.99$, $p=0.026)$, and the " $\mathrm{T}$ " allele increased the risk in the log-additive model $(\mathrm{OR}=1.36 ; 95 \% \mathrm{CI}, 1.02-1.79, p$ $=0.034)$. After the Bonferroni correction, mutations at rs10069690 (dominant $p=1.732 \mathrm{E}-04$; additive $p<0.005$ ) and rs2242652 (dominant $p=0.016$; additive $p=0.024$ ) were still associated with an increased risk of esophageal cancer.

TERT polymorphisms were further characterized using linkage disequilibrium (LD) and haplotype analyses. LD was determined pairwise among all four SNPs, the haplotype structure of the TERT gene was analyzed, and single LD blocks consisting of two SNPs (rs10069690 and 2242652) were detected (Figure 1).

Finally, a haplotype-based association study was performed to examine associations between TERT haplotype and risk of esophageal cancer (Table 4), and $p$ values were calculated using the Wald test. After adjusting for age and gender, the "TA" (95\% CI, 1.91 - 2.12; $p=0.002)$ and "TG" (95\% CI, $1.20-11.1 ; p=0.022)$ haplotypes increased the risk of esophageal cancer 1.59fold and 3.66-fold, respectively. In contrast, the "CG" haplotype was associated with a 0.61 -fold decrease in the risk of esophageal cancer $(95 \% \mathrm{CI}, 0.46-0.81 ; p<$ $0.001)$.

\section{DISCUSSION}

In the present study, we systematically examined the impact of four SNPs in the TERT loci on susceptibility to esophageal cancer. We found that the rs10069690, rs2242652, and rs2853676 TERT genetic polymorphisms were associated with an increased risk of esophageal cancer in a northwestern Chinese patient population. To the best of our knowledge, this is the first case-control study to investigate this association.

The incidence of esophageal cancer is increasing worldwide. For example, in the United States, the incidence of esophageal cancer has increased six-fold over the last three decades [19]. Meanwhile, the incidence of SCC has remained stable in Europe and the United States $[8,10]$. Furthermore, while the incidence of SCC remained constant in males, it increased slightly in females, in whom rates of smoking have also increased in recent decades. Genetic and environmental factors both play important roles in cancer pathogenesis. For example, nitrosamine exposure resulting from tobacco use has been associated with an increased risk of esophageal cancer $[20,21]$. In addition, alcohol consumption is a risk factor 
Table 1: General characteristics the of this study population

\begin{tabular}{lcc}
\hline \multirow{2}{*}{ Variable } & Cases & Controls \\
\cline { 2 - 3 } Gender & $\mathbf{n = 3 8 6}$ & $\mathbf{n}=\mathbf{4 9 5}$ \\
Male & $308(79.8 \%)$ & $180(36.4 \%)$ \\
Female & $78(20.2 \%)$ & $315(63.6 \%)$ \\
Age, year $(\operatorname{mean} \pm \mathrm{SD})$ & $60.68 \pm 8.954$ & $54.48 \pm 9.438$ \\
\hline
\end{tabular}

Table 2: Frequency distributions of $T E R T$ alleles and their associations with esophageal cancer risk

\begin{tabular}{|c|c|c|c|c|c|c|c|c|}
\hline \multirow{2}{*}{ SNP ID } & \multirow{2}{*}{ Position } & \multirow{2}{*}{$\begin{array}{c}\text { Allele } \\
\mathbf{A} * / \mathbf{B}\end{array}$} & \multicolumn{2}{|c|}{ MAF } & \multirow{2}{*}{ HWE-p } & \multirow{2}{*}{ ORs (95\% CI) } & \multirow{2}{*}{${ }^{\mathrm{a}} p$-value } & \multirow{2}{*}{${ }^{\mathrm{b}} p$-value } \\
\hline & & & Cases & Controls & & & & \\
\hline rs10069690 & 1279790 & $\mathrm{~T} / \mathrm{C}$ & 0.22 & 0.14 & 0.27 & $1.70(1.33-2.18)$ & $2.50 \mathrm{E}-05$ & 1.0E-04 \\
\hline rs2242652 & 1280028 & $\mathrm{~A} / \mathrm{G}$ & 0.23 & 0.16 & 1 & $1.48(1.17-1.89)$ & 0.001 & 0.004 \\
\hline rs2853677 & 1287194 & $\mathrm{G} / \mathrm{A}$ & 0.40 & 0.38 & 0.44 & $1.14(0.93-1.38)$ & 0.200 & 0.800 \\
\hline rs 2853676 & 1288547 & $\mathrm{~T} / \mathrm{C}$ & 0.20 & 0.16 & 0.50 & $1.33(1.04-1.70)$ & 0.023 & 0.092 \\
\hline
\end{tabular}

Abbreviations: SNP = single nucleotide polymorphism, CI = confidence interval, HWE = Hardy-Weinberg Equilibrium, $\mathrm{MAF}=$ minor allele frequency, ORs $=$ odds ratios.

Notes: *Minor allele; ${ }^{\mathrm{a}} p$-values were calculated from two-sided Pearson chi-square tests for either allele frequency and ${ }^{\mathrm{b}} p$ values were adjusted by Bonferroni correction; $p$-value $<0.05$ indicates statistical significance.

Table 3: Genotypic model analysis of relationship between SNPs and esophageal cancer risk

\begin{tabular}{|c|c|c|c|c|c|c|c|c|c|}
\hline \multirow[b]{2}{*}{ SNP } & \multirow[b]{2}{*}{ Model } & \multirow[b]{2}{*}{ Genotype } & \multirow[b]{2}{*}{ Cases } & \multirow[b]{2}{*}{ Controls } & \multicolumn{2}{|c|}{ Without adjustment } & \multicolumn{2}{|c|}{ With adjustment } & \multirow[b]{2}{*}{${ }^{\mathrm{b}} p$-value } \\
\hline & & & & & $\begin{array}{c}\text { ORs } \\
(95 \% \mathrm{CI})\end{array}$ & p-value & $\begin{array}{c}\text { ORs } \\
(95 \% \mathrm{CI})\end{array}$ & $\begin{array}{c}{ }^{\mathrm{a}} p- \\
\text { value }\end{array}$ & \\
\hline \multirow[t]{5}{*}{ rs10069690 } & Dominant & $\mathrm{C} / \mathrm{C}$ & 227 & 359 & 1 & & & & \\
\hline & & $\mathrm{T} / \mathrm{C}-\mathrm{T} / \mathrm{T}$ & 155 & 126 & $\begin{array}{c}1.95 \\
(1.46-2.60)\end{array}$ & 5.89E-06 & $\begin{array}{c}1.97 \\
(1.43-2.73)\end{array}$ & $\begin{array}{c}\text { 4.33E- } \\
05\end{array}$ & $\begin{array}{c}\text { 1.732E- } \\
04\end{array}$ \\
\hline & Recessive & $\mathrm{C} / \mathrm{C}-\mathrm{C} / \mathrm{T}$ & 368 & 472 & 1 & & & & \\
\hline & & $\mathrm{TT}$ & 14 & 13 & $\begin{array}{c}1.39 \\
(0.64-2.96)\end{array}$ & 0.41 & $\begin{array}{c}1.48 \\
(0.62-3.51)\end{array}$ & 0.3794 & 1 \\
\hline & Log-additive & - & - & - & $\begin{array}{c}1.71 \\
(1.33-2.20)\end{array}$ & 3.02E-05 & $\begin{array}{c}1.73 \\
(1.31-2.31)\end{array}$ & $<0.001$ & $<0.005$ \\
\hline \multirow[t]{5}{*}{ rs2242652 } & Dominant & $\mathrm{G} / \mathrm{G}$ & 224 & 346 & 1 & & & & \\
\hline & & $\mathrm{G} / \mathrm{A}-\mathrm{A} / \mathrm{A}$ & 158 & 149 & $\begin{array}{c}1.64 \\
(1.24-2.17)\end{array}$ & $5.5 \mathrm{E}-04$ & $\begin{array}{c}1.59 \\
(1.16-2.18)\end{array}$ & 0.004 & 0.016 \\
\hline & Recessive & G/G-G/A & 368 & 482 & 1 & & & & \\
\hline & & $\mathrm{A} / \mathrm{A}$ & 14 & 13 & $\begin{array}{c}1.41 \\
(0.66-3.04)\end{array}$ & 0.38 & $\begin{array}{c}1.48 \\
(0.62-3.50)\end{array}$ & 0.378 & 1 \\
\hline & Log-additive & - & - & - & $\begin{array}{c}1.51 \\
(1.18-1.93)\end{array}$ & 0.001 & $\begin{array}{c}1.48 \\
(1.12-1.95)\end{array}$ & 0.006 & 0.024 \\
\hline \multirow[t]{2}{*}{ rs2853676 } & Dominant & $\mathrm{C} / \mathrm{C}$ & 248 & 355 & 1 & & & & \\
\hline & & $\mathrm{C} / \mathrm{T}-\mathrm{T} / \mathrm{T}$ & 138 & 140 & $\begin{array}{c}1.41 \\
(1.06-1.88)\end{array}$ & 0.18 & $\begin{array}{c}1.44 \\
(1.05-1.99)\end{array}$ & 0.026 & 0.104 \\
\hline
\end{tabular}

(Continued) 


\begin{tabular}{|c|c|c|c|c|c|c|c|c|c|}
\hline \multirow[b]{2}{*}{ SNP } & \multirow[b]{2}{*}{ Model } & \multirow[b]{2}{*}{ Genotype } & \multirow[b]{2}{*}{ Cases } & \multirow[b]{2}{*}{ Controls } & \multicolumn{2}{|c|}{ Without adjustment } & \multicolumn{2}{|c|}{ With adjustment } & \multirow[b]{2}{*}{${ }^{\mathrm{b}} p$-value } \\
\hline & & & & & $\begin{array}{c}\text { ORs } \\
(95 \% \text { CI })\end{array}$ & p-value & $\begin{array}{c}\text { ORs } \\
(95 \% \mathrm{CI})\end{array}$ & $\begin{array}{c}{ }^{\mathrm{a} p} p- \\
\text { value }\end{array}$ & \\
\hline \multirow{8}{*}{ rs2853677 } & Recessive & $\mathrm{C} / \mathrm{T}-\mathrm{T} / \mathrm{T}$ & 372 & 481 & 1 & & & & \\
\hline & & $\mathrm{T} / \mathrm{T}$ & 14 & 14 & $\begin{array}{c}1.29 \\
(0.61-2.75)\end{array}$ & 0.5 & $\begin{array}{c}1.33 \\
(0.56-3.12)\end{array}$ & 0.520 & 1 \\
\hline & Log-additive & - & - & - & $\begin{array}{c}1.33 \\
(1.04-1.70)\end{array}$ & 0.24 & $\begin{array}{c}1.36 \\
(1.02-1.79)\end{array}$ & 0.034 & 1 \\
\hline & Dominant & $\mathrm{AA}$ & 140 & 202 & 1 & & 1 & & \\
\hline & & A/G-G/G & 241 & 293 & $\begin{array}{c}1.19 \\
(0.90-1.56)\end{array}$ & 0.22 & $\begin{array}{c}1.26 \\
(0.92-1.71)\end{array}$ & 0.15 & 0.60 \\
\hline & Recessive & A/G-A/A & 319 & 424 & 1 & & 1 & & \\
\hline & & $\mathrm{G} / \mathrm{G}$ & 62 & 71 & $\begin{array}{c}1.16 \\
(0.80-1.68)\end{array}$ & 0.43 & $\begin{array}{c}1.39 \\
(0.91-2.12)\end{array}$ & 0.13 & 0.52 \\
\hline & Log-additive & - & - & - & $\begin{array}{c}1.13 \\
(0.93-1.37)\end{array}$ & 0.21 & $\begin{array}{c}1.22 \\
(0.98-1.52)\end{array}$ & 0.07 & 0.28 \\
\hline
\end{tabular}

Abbreviations: $\mathrm{CI}=$ confidence interval, $\mathrm{OR}=$ odds ratio, $\mathrm{SNP}=$ single nucleotide polymorphism.

Notes: $p$-values were calculated by Wald test and $p$-value $<0.05$ indicates statistical significance; ${ }^{\mathrm{a}} p$-value were adjusted by gender and age and ${ }^{\mathrm{b}} p$-value were adjusted by Bonferroni correction.

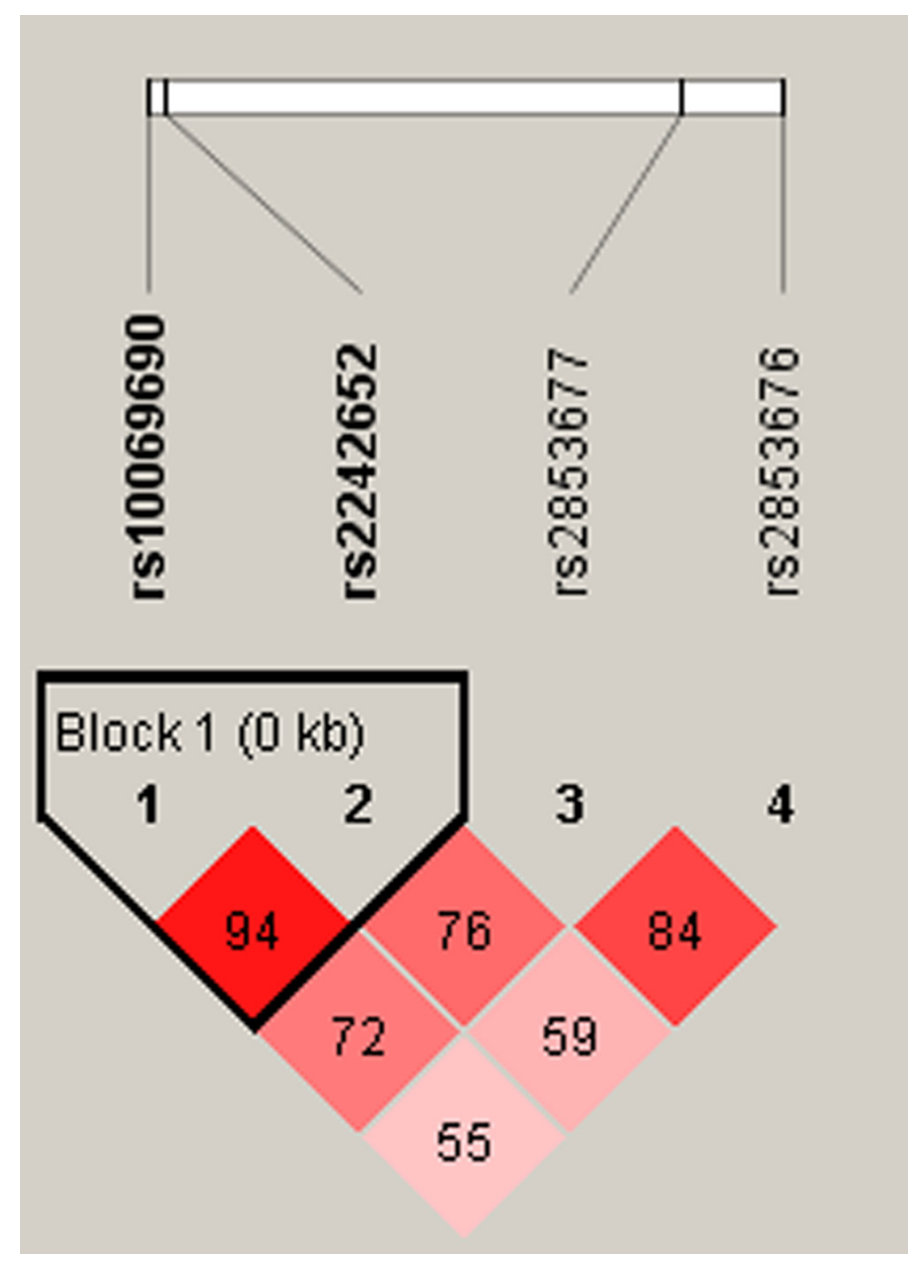

Figure 1: Linkage disequilibrium patterns for four TERT SNPs. 
Table 4: Haplotype analysis results in this study

\begin{tabular}{|c|c|c|c|c|c|c|c|}
\hline \multicolumn{2}{|c|}{ Haplotype } & \multicolumn{2}{|c|}{ Frequency } & \multicolumn{2}{|c|}{ Without adjustment } & \multicolumn{2}{|c|}{ With adjustment } \\
\hline rs10069690 & rs2242652 & Cases & Controls & ORs (95\% CI) & $p$-value & ORs (95\% CI) & $p$-value* \\
\hline $\mathrm{T}$ & A & 0.206 & 0.137 & $1.63(1.26-2.11)$ & $<0.001$ & $1.59(1.91-2.12)$ & 0.002 \\
\hline $\mathrm{C}$ & A & 0.017 & 0.02 & $0.87(0.43-1.79)$ & 0.71 & $0.83(0.37-1.84)$ & 0.641 \\
\hline $\mathrm{T}$ & G & 0.015 & 0.006 & $2.38(0.87-6.51)$ & 0.08 & $3.66(1.20-11.1)$ & 0.022 \\
\hline $\mathrm{C}$ & $\mathrm{G}$ & 0.762 & 0.837 & $0.61(0.47-0.78)$ & $<0.001$ & $0.61(0.46-0.81)$ & $<0.001$ \\
\hline
\end{tabular}

Abbreviations: $\mathrm{CI}=$ confidence interval, $\mathrm{OR}=$ odds ratio, $\mathrm{SNP}=$ single nucleotide polymorphism.

Notes: $p$-values were calculated by Wald test and $p$-value $<0.05$ indicates statistical significance;

*Adjusted by gender and age.

for ESCC, but not for adenocarcinoma [21, 22]. Other important factors include low socioeconomic status, poor oral hygiene, and nutritional deficiencies [23-25].

As the main catalytic subunit of telomerase, TERT is essential for the maintenance of telomere DNA length in chromosomes [13]. Telomerase is an RNA-dependent DNA polymerase that synthesizes repeating TTAGGG DNA sequences, which bind many specialized proteins to the ends of the chromosome [26]. Telomeres prevent coding sequence erosion and protect chromosomes from rearrangements, fusion, and genome instability by aiding in complete chromosome replication and regulating gene expression [27]. The activation of telomerase is a vital step during cellular immortalization and malignant transformation in human cells, and many human malignancies are characterized by elevated TERT expression. TERT may therefore play an important role in cancer pathogenesis $[13,28]$. The TERT gene sequence in general is thought to be indicative of an individual's susceptibility to cancer [29-31], and epidemiological studies have identified associations between specific TERT polymorphisms and cancer development [29, 30].

Rs 10069690 was originally discovered in a genomewide association study of AAs [32], and we suspected that this SNP might also affect the risk of developing esophageal cancer. Another previous study found that the variant allele at TERT rs 4246742 was inversely associated with breast cancer risk, while positive associations were found for rs10069690 (OR = 1.13), rs2242652 (OR = 1.51), and rs2853676 (OR 1.23) [33]. The rs2853676 polymorphism is also associated with an increased risk of glioma [34]. The additive ORs of the rs 2853676 and rs2242652 SNPs for the risk of melanoma were 1.43 and 1.50, respectively [35]. Certain rs 10069690 and rs 2242652 SNP alleles are also associated with increased risk of estrogen receptor-negative cancers $[14,36]$. Furthermore, recent studies have shown that rs 2853677 is associated with the risk of lung adenocarcinoma in Japanese [37] and European [38] populations. Here, we found that the rs10069690, rs2242652, and rs2853676 TERT genetic polymorphisms were associated with an increased risk of esophageal cancer in a northwestern Chinese patient population; subsequent studies should be conducted to examine these associations in patients from other regions and ethnic groups.

We also identified an LD block consisting of the rs 10069690 and 2242652 SNPs, both of which increased susceptibility to esophageal cancer. A previous study found that the rare $\mathrm{G}_{\mathrm{rs} 4246742} \mathrm{~A}_{\mathrm{rs} 2736100} \mathrm{~T}_{\mathrm{rs} 2853676}$ TERT haplotype was directly associated with telomere length [39]. Future studies should evaluate the association between the rs4246742 andrs2736100 SNPs and susceptibility to esophageal cancer.

Some limitations of the present study should be considered when interpreting the results. First, although there was sufficient statistical power for our analyses, the sample size in this study was relatively small. Second, associations between TERT polymorphisms and clinicopathological disease type were not evaluated in this study, and larger, well-designed studies are needed to confirm the associations observed here. Finally, both esophageal cancer patients and controls were enrolled at a single hospital and therefore may not be representative of the general population. Additional studies are needed to clarify the genetic mechanisms underlying esophageal carcinogenesis by fine-mapping the susceptibility regions of the variants.

In conclusion, we demonstrated that the rs10069690, rs2242652, and rs2853676 genetic polymorphisms in the TERT loci are associated with an increased risk of esophageal cancer in a northwestern Chinese patient population. Our results demonstrate the complex genetic regulation of telomere biology and the crucial role of telomerase in carcinogenesis. These results may also help improve the understanding of inter-population differences in esophageal cancer etiology, although the biological functions of these TERT SNPs need to be investigated in future studies. Finally, the esophageal cancer-associated molecular markers identified here might be useful as diagnostic and prognostic markers for esophageal cancer patient in future clinical studies. 


\section{MATERIALS AND METHODS}

\section{Ethics and consent}

All subjects were informed of the purpose of the study and the experimental procedures involved. The Human Research Committee of the Tangdu Hospital for Approval of Research Involving Human Subjects approved the use of human tissue in this study. We also obtained signed informed consent from all participants.

\section{Study participants}

386 patients were recruited between August 2012 and July 2016 to participate in an ongoing molecular epidemiological study at the Department of Respiratory Physicians of the Tangdu Hospital affiliated with The Fourth Military Medical University in Xi'an, China. All subjects were screened by examining endoscopic staining with $1.2 \%$ iodine solution, and biopsies were taken from non-staining stained mucosal areas for each patient. Tissue sections were reviewed by two experienced pathologists to ensure that tumor cell purity was greater than $50 \%$ and to confirm histological type. None of the patients had a history of other cancers, nor did they receive chemotherapy or radiotherapy prior to this study. Patients with any comorbidity, such as diabetes mellitus, hypertension, or an endocrine disorder, were excluded. We also recruited 495 unrelated healthy individuals at random during the same period at the medical center of Tangdu Hospital to serve as controls. All study participants lived in or near Xi' an. Control group individuals had no history of known medical illness or hereditary disorders and were not taking any medications.

\section{SNP selection and genotyping}

We examined four single nucleotide polymorphisms (SNPs) in TERT that had minor allele frequencies (MAF) greater than $5 \%$. Samples were centrifuged and stored at $-80^{\circ}$ until analysis. We extracted genomic DNA from peripheral blood samples using the GoldMag-Mini Whole Blood Genomic DNA Purification Kit (GoldMag Ltd. Xi'an, China) according to the manufacturer's protocol and measured DNA concentrations using a NanoDrop 2000. Sequenom MassARRAY Assay Design 3.0 Software was used to design primers for amplification and extension reactions [40]. SNP genotyping was performed using a Sequenom MassARRAY RS1000 according to the manufacturer's standard protocol [40]. Finally, Sequenom Typer 4.0 Software was used for data management and analysis $[40,41]$.

\section{Statistical analysis}

Departure from Hardy-Weinberg Equilibrium (HWE) was assessed for the frequency of each SNP using an exact test on the control subjects. Differences in genotype frequencies between the esophageal cancer and control groups were evaluated using the Chi-square test [42]. Microsoft Excel and the SPSS 17.0 statistical package (SPSS, Chicago, IL) were used for statistical analyses. All $p$-values presented in this study are twosided; $p \leq 0.05$ was considered statistically significant. Odds ratios (OR) and 95\% confidence intervals (CI) were calculated using unconditional logistic regression analyses [43]. The web-based software SNP Stats was used to identify associations between SNPs and the risk of esophageal cancer in three genetic models (dominant, recessive, and additive) [44]. We used the Haploview software package (version 4.2) and the SHEsis software platform (http://www.nhgg.org/analysis/) to analyze linkage disequilibrium, haplotype construction, and genetic associations at polymorphism loci $[45,46]$.

\section{ACKNOWLEDGMENTS}

This work was supported by the Science Foundation of Northwest University (Nos. 15NW19 and 338020007). We are grateful to the patients for their participation.

\section{CONFLICTS OF INTEREST}

The authors declare that they have no competing interests.

\section{REFERENCES}

1. JF, Shin HR, Bray F, Forman D, Mathers C, Parkin DM. Estimates of worldwide burden of cancer in 2008: GLOBOCAN 2008. International Journal of Cancer. 2010; 127:2893-2917.

2. Chen W, He Y, Zheng R, Zhang S, Zeng H, Zou X, He J. Esophageal cancer incidence and mortality in China, 2009. Journal of thoracic disease. 2013; 5:19-26.

3. Jemal A, Siegel R, Ward E, Hao Y, Xu J, Murray T, Thun MJ. Cancer statistics, 2008. Ca. 2009; 59:225-249.

4. Holmes RS, Vaughan TL. (2007). Epidemiology and Pathogenesis of Esophageal Cancer. Seminars in Radiation Oncology, pp. 2-9.

5. Macfarlane GJ, Boyle P. The epidemiology of oesophageal cancer in the UK and other European countries. Journal of the Royal Society of Medicine. 1994; 87:334-337.

6. Allen DC. Oesophageal carcinoma. Lancet. 2013; 381:400-412.

7. Secretan B, Straif K, Baan R, Grosse Y, Ghissassi FE, Bouvard V, Benbrahim-Tallaa L, Guha N, Freeman C, Galichet L. A review of human carcinogens-Part E: tobacco, areca nut, alcohol, coal smoke, and salted fish. Lancet Oncology. 2009; 10:1033-1034. 
8. Cook MB, Chow WH, Devesa SS. Oesophageal cancer incidence in the United States by race, sex, and histologic type, 1977-2005. British Journal of Cancer. 2009; 101:855-859.

9. Pohl H, Welch HG. The role of overdiagnosis and reclassification in the marked increase of esophageal adenocarcinoma incidence. Journal of the National Cancer Institute. 2005; 97:142-146.

10. CB, Levi F, Ferlay J, Garavello W, Lucchini F, Bertuccio $\mathrm{P}$, Negri E, Vecchia CL. Trends in oesophageal cancer incidence and mortality in Europe. International Journal of Cancer. 2008; 122:1118-1129.

11. Hongo M. Review article: Barrett's oesophagus and carcinoma in Japan. Alimentary Pharmacology \& Therapeutics. 2004; 20 Suppl 8:50-54.

12. Rodier F, Kim SH, Nijjar T, Yaswen P, Campisi J. Cancer and aging: the importance of telomeres in genome maintenance. International Journal of Biochemistry \& Cell Biology. 2005; 37:977-990.

13. Young NS. Telomere biology and telomere diseases: implications for practice and research. Hematology. 2010; 2010:30-35

14. Bojesen SE, Pooley KA, Johnatty SE, Beesley J, Michailidou K, Tyrer JP, Edwards SL, Pickett HA, Shen HC, Smart CE. Multiple independent variants at the TERT locus are associated with telomere length and risks of breast and ovarian cancer. Nature Genetics. 2013; 45:371-384.

15. Jones AM, Beggs AD, Carvajal-Carmona L, Farrington S, Tenesa A, Walker M, Howarth K, Ballereau S, Hodgson SV, Zauber A. TERC polymorphisms are associated both with susceptibility to colorectal cancer and with longer telomeres. Gut. 2011; 61:248-254.

16. Lü MH, Deng JQ, Cao YL, Fang DC, Zhang Y, Yang SM. Prognostic role of telomerase activity in gastric adenocarcinoma: A meta-analysis. Experimental \& Therapeutic Medicine. 2012; 3:728-734.

17. Okawa T, Michaylira CZ, Kalabis J, Stairs DB, Nakagawa $\mathrm{H}$, Andl C, Johnstone CN, Kleinszanto AJ, Eldeiry WS, Cukierman E. The functional interplay between EGFR overexpression, hTERT activation, and p53 mutation in esophageal epithelial cells with activation of stromal fibroblasts induces tumor development, invasion, and differentiation. Genes \& Development. 2007; 21:2788-2803.

18. Chen PC, Peng JR, Huang L, Li WX, Wang WZ, Cui ZQ, Han H, Gong L, Xiang DP, Qiao SS. Overexpression of human telomerase reverse transcriptase promotes the motility and invasiveness of HepG2 cells in vitro. Oncology Reports. 2013; 30:1157-1164.

19. Pohl H, Welch HG. The role of overdiagnosis and reclassification in the marked increase of esophageal adenocarcinoma incidence. Journal of the National Cancer Institute. 2005; 97:1014-1014.

20. Vaughan TL, Davis S, Kristal A, Thomas DB. Obesity, alcohol, and tobacco as risk factors for cancers of the esophagus and gastric cardia: adenocarcinoma versus squamous cell carcinoma. Cancer Epidemiology Biomarkers \& Prevention. 1995; 4:85-92.

21. Gammon MD, Schoenberg JB, Ahsan H, Risch HA, Vaughan TL, Chow WH, Rotterdam H, West AB, Dubrow $\mathrm{R}$, Stanford JL. Tobacco, alcohol, and socioeconomic status and adenocarcinomas of the esophagus and gastric cardia. Journal of the National Cancer Institute. 1997; 89.

22. Lee CH, Wu DC, Lee JM, Wu IC, Goan YG, Kao EL, Huang HL, Chan TF, Chou SH, Chou YP. Carcinogenetic impact of alcohol intake on squamous cell carcinoma risk of the oesophagus in relation to tobacco smoking. European Journal of Cancer. 2007; 43:1188-1199.

23. Enzinger PC, Mayer RJ. Esophageal cancer. New England Journal of Medicine. 2003; 349:2241-2252.

24. Taylor PR, Qiao YL, Abnet CC, Wen W, Dawsey SM, Yang CS, Gunter E, Blot WJ, Dong ZW, Mark SD. Prospective study of serum vitamin E levels and esophageal and gastric cancers. Cancerspectrum Knowledge Environment. 2003; 95:1414-1416.

25. Abnet CC, Lai B, Qiao YL, Vogt S, Luo XM, Taylor PR, Dong ZW, Mark SD, Dawsey SM. Zinc concentration in esophageal biopsy specimens measured by $\mathrm{x}$-ray fluorescence and esophageal cancer risk. Journal of the National Cancer Institute. 2005; 97:301-306.

26. Cong YS, Wright WE, Shay JW. Human Telomerase and Its Regulation. Microbiol Mol Biol Rev. 2002; 66: 407-425.

27. Pooley KA, Sandhu MS, Tyrer J, Shah M, Driver KE, Luben RN, Bingham SA, Ponder BAJ, Pharoah PDP, Khaw KT. Telomere Length in Prospective and Retrospective Cancer Case-Control Studies. Cancer Research. 2010; 70:3170-3176.

28. Zachos I, Konstantinopoulos PA, Vandoros GP, Karamouzis MV, Papatsoris AG, Podimatas T, Papachristodoulou A, Chrisofos M, Deliveliotis C, Papavassiliou AG. Predictive value of telomerase reverse transcriptase expression in patients with high risk superficial bladder cancer treated with adjuvant BCG immunotherapy. Journal of Cancer Research \& Clinical Oncology. 2009; 135:1169-1175.

29. Park SL, Fesinmeyer MD, Timofeeva M, Caberto CP, Kocarnik JM, Han Y, Love SA, Young A, Dumitrescu L, Lin Y. Pleiotropic associations of risk variants identified for other cancers with lung cancer risk: the PAGE and TRICL consortia. Journal of the National Cancer Institute. 2014; 106:dju061-dju061.

30. Rafnar T, Sulem P, Stacey SN, Geller F, Gudmundsson J, Sigurdsson A, Jakobsdottir M, Helgadottir H, Thorlacius $\mathrm{S}$, Aben KKH. Sequence variants at the TERT-CLPTM1L locus associate with many cancer types. Nature Genetics. 2009; 41:221-227.

31. Yin J, Li Y, Yin M, Sun J, Liu L, Qin Q, Li X, Long L, Nie S, Wei S. TERT-CLPTM1L polymorphism rs401681 contributes to cancers risk: evidence from a meta-analysis based on 29 publications. Plos One. 2012; 7:154-159. 
32. Haiman CA, Chen GK, Vachon CM, Canzian F, Dunning A, Millikan RC, Wang X, Ademuyiwa F, Ahmed S, Ambrosone CB. A common variant at the TERT-CLPTM1L locus is associated with estrogen receptor-negative breast cancer. Nature Genetics. 2011; 43:1210-1214.

33. Pellatt AJ, Wolff RK, Torres-Mejia G, John EM, Herrick JS, Lundgreen A, Baumgartner KB, Giuliano AR, Hines LM, Fejerman L. Telomere length, telomere-related genes, and breast cancer risk: The breast cancer health disparities study. Genes Chromosomes \& Cancer. 2013; 52:595-609.

34. Shete S, Hosking FJ, Robertson LB, Dobbins SE, Sanson M, Malmer B, Simon M, Marie Y, Boisselier B, Delattre JY. Genome-wide association study identifies five susceptibility loci for glioma. Nature Genetics. 2009; 41:899-904.

35. Nan H, Qureshi AA, Prescott J, Vivo ID, Han J. Genetic variants in telomere-maintaining genes and skin cancer risk. Human Genetics. 2011; 129:247-253.

36. Liu JP. Molecular mechanisms of ageing and related diseases. Clinical \& Experimental Pharmacology \& Physiology. 2014; 41:445-458.

37. Shiraishi K, Kunitoh H, Daigo Y, Takahashi A, Goto K, Sakamoto H, Ohnami S, Shimada Y, Ashikawa K, Saito A. A genome-wide association study identifies two new susceptibility loci for lung adenocarcinoma in the Japanese population. Nature Genetics. 2012; 44:900-903.

38. Brenner DR, Brennan P, Boffetta P, Amos CI, Spitz MR, Chen C, Goodman G, Heinrich J, Bickeböller H, Rosenberger A. Hierarchical modeling identifies novel lung cancer susceptibility variants in inflammation pathways among 10,140 cases and 11,012 controls. Human Genetics. 2013; 132:579-589.
39. Pellatt AJ, Wolff RK, Lundgreen A, Cawthon R, Slattery ML. Genetic and lifestyle influence on telomere length and subsequent risk of colon cancer in a case control study. International Journal of Molecular Epidemiology \& Genetics. 2011; 3:184-194.

40. Gabriel S, Ziaugra L, Tabbaa D. SNP genotyping using the Sequenom MassARRAY iPLEX platform. Current protocols in human genetics. 2009:2.12. 11-12.12. 16.

41. Thomas RK, Baker AC, DeBiasi RM, Winckler W, LaFramboise T, Lin WM, Wang M, Feng W, Zander T, MacConaill LE. High-throughput oncogene mutation profiling in human cancer. Nature genetics. 2007; 39:347-351.

42. Adamec C. [EXAMPLE OF THE USE OF THE NONPARAMETRIC TEST. TEST X2 FOR COMPARISON OF 2 INDEPENDENT EXAMPLES.]. Ceskoslovenske zdravotnictvi. 1964; 12:613-619.

43. Bland JM, Altman DG. The odds ratio. Bmj. 2000; 320:1468.

44. Sole X, Guino E, Valls J, Iniesta R, Moreno V. SNPStats: a web tool for the analysis of association studies. Bioinformatics. 2006; 22:1928-1929.

45. Barrett JC, Fry B, Maller J, Daly MJ. Haploview: analysis and visualization of LD and haplotype maps. Bioinformatics. 2005; 21:263-265.

46. Yong YS, Lin HE. SHEsis, a powerful software platform for analyses of linkage disequilibrium, haplotype construction, and genetic association at polymorphism loci. Cell Research. 2005; 15:97-98. 